\title{
EMPLOYEES DISCRIMINATION ISSUES BASED ON THE STATISTICAL ANALYSIS USING SPSS (Case of Georgia, Republic of)
}

\author{
Nino Paresashvili ${ }^{1}$, Mzia Tikishvili ${ }^{2}$, Teona Edzgveradze ${ }^{3}$ \\ 1, 2, 3 Ivane Javakhishvili State University, Tbilisi, Georgia \\ e-mails: ${ }^{1}$ nino.paresashvili@tsu.ge, ${ }^{2}$ mzia.tikishvilii@bntu.edu.ge, ${ }^{3}$ teoedzgveradze85@gmail.com
}

Received: 20 March 2021; Accepted: 10 May 2021 Published: 21 May 2021

\begin{abstract}
Every single person has right to work in a free and fair environment. But unfortunately, there are some cases all over the world which show that the situation in the workplaces is opposite. There are different types of discrimination of employees. That is why it is so much important to study the basis of all the types discrimination, find out the crucial problems in each one and work out the relevant solutions to facilitate the victims or potential victims for the improvement of their working conditions.

The paper studies employee's discrimination issues in the organization. For leading the management of the organization efficiently, it is of great importance to conduct a detailed study of the ongoing processes, analyze the results of the study and develop measures based on the information received as a result of the analysis for improving the management.

The purpose of the present paper is to identify discrimination in the organization for further prevention of such facts. For this purpose, a special questionnaire was developed.

The Methodology Statistical analysis of discrimination issues was made using the Statistical Package for the Social Sciences (SPSS). The questionnaire was filled out by 488 respondents living and working in Georgia. 5 hypotheses were determined in order to find out the correlation between some indicators and their impact level to discrimination in the workplace. Evaluation of the impact of those indicators was performed using Multiple Analysis of Variance (MANOVA) by using multivariate analysis.
\end{abstract}

Keywords: Discrimination, employee, workplace, organizational policy and culture.

JEL classification: M12, M51, M54

Citation:

Paresashvili, N., Tikishvili, M., Edzgveradze, T. (2021). Employees discrimination issues based on the statistical analysis using SPSS (Case of Georgia, Republic of). Access to science, business, innovation in digital economy, ACCESS Press, 2(2): 175-191. https://doi.org/10.46656/access.2021.2.2(5)

\section{INTRODUCTION}

In the conditions of modern globalization, human capital is the most important factor in terms of the competitiveness and development of the country and its economy in the world market. (Paresashvili et al, 2021). For Georgia, like for any other country, reproduction of human capital, which responds to the modern challenges of the innovative economy is the main condition for economic growth. High unemployment, which causes quite negative economic and social consequences in the daily life of any country, represents the most important barrier to full utilization of human capital. (Paresashvili, Okruashvili, \& Edzgveradze, 2020).

Discrimination may be charged using two legal theories. The first is disparate treatment, in which there is evidence that members of protected groups are treated differently. The second legal theory is adverse (or 
disparate) impact, in which members of protected groups are adversely affected by employment practices that may not initially appear discriminatory. For example, employment practices not explicitly intended to be discriminatory (such as the use of ability tests and high school diplomas) may nonetheless be viewed as such if they result in inferior outcomes for a protected class (if, additionally, they are not demonstrably job-related (Sims, 2018). Discrimination means refusing to employ, barring from employment, or discriminating in compensation or terms, conditions, and privileges of employment. Employers also can't print or circulate statements, advertisements or publications, use job applications, or make pre- employment inquiries that directly or indirectly express any actual or intended limitation, specification, or discrimination regarding a protected class, unless this restriction is based on a bona fide occupation Employers and their employees can't aid, abet, incite, compel, or coerce unlawful discriminatory acts or try to do so. The opportunity to obtain employment without discrimination based on protected classes is considered a civil right (NCSL, Bloomberg Law, 2019).

Employment discrimination happens when an employee or job candidate is treated unfavorably because of age, disability, genetic information, national origin, pregnancy, race or skin color, religion, or sex. In addition, federal laws against discrimination protect workers from retaliation for "asserting their rights to be free from employment discrimination" (U.S. Equal Employment Opportunity Commission, 2020). Workplace discrimination occurs when an individual is discriminated against due to any number of factors. In addition to the reasons listed above, employees and job applicants can also be discriminated against because of their relationship to another person (EEOC, 2020).

There are different tyoe of discrimination like gender, age, Physical, intellectual, mental or psychiatric disability, Pregnancy or potential pregnancy, Marital status, relationship status and family or carer's responsibilities, Religion, Political opinion. But It should be noted also, that in order to dicuss about discrimination in a relevant way we should differ it from harrasment or other type violence in the workplace:

- Discrimination occurs where someone is treated less favourably due to a particular protected attribute, even if the treatment isn't openly antagonistic - for example, not getting a promotion because you are pregnant, or being the subject of "joking banter" by reference to that protected attribute - and even where it is indirect - for example an employer may say they are open to employing people with disabilities, but do not provide appropriate access;

- Harassment is when someone is treated in a way that is offensive, humiliating, intimidating or threatening because of a particular attribute like coming from another country;

- Sexual harassment is unwelcome advances or attention of a sexual nature;

- Bullying is repeated unreasonable behaviour that places the affected person's health or wellbeing at risk.

Bullying and harassment are considered discriminatory behaviour if they are motivated by a protected attribute of the victim, like a disability (MDC Legal, 2017) al qualification. 
The main aim of the article is to investigate the most acute problems in the labor market of the country and outline the most effective management mechanisms in order to solve them. More concretely, the purpose of the present paper is to identify discrimination in the organization for further prevention of such facts. For this purpose, a special questionnaire was developed. The questionnaire was filled out by 488 respondents. Statistical analysis of discrimination issues was made using the Statistical Package for the Social Sciences (SPSS).

\section{LITERATURE REVIEW}

COVID-19 has shifted a significant portion of business around the world into a phase of economic uncertainty. (Paresashvili et al, 2021).

Job satisfaction affects a number of organizational behaviors and can greatly determine employee wellbeing. (Paresashvili, Okruashvili, \& Chitaladze, 2021). Furthermore, Human Resource (HR) professionals together with management should make more effort to feel employees involved in organizational processes again, to strengthen their organizational culture and adaptation motivational systems. Every organization has specific style, specific rules, policy and situations which cannot be combine in general rules (Maisuradze, 2017). It is inconceivable to discuss discrimination issues without organizational conflicts, on which quite a lot of research has been done. (Paresashvili et al, 2020). Today, there are rich scientific literature on organizational conflicts conducted by foreign and Georgian researchers, which analyzes a number of issues directly related to conflict management. One of them is the topic of career development. (Paresashvili et al, 2019).

The most important thing for each individual is career advancement and professional growth, in which issues of managing organizational conflicts are quite important, (Paichadze et al, 2019), because it is quite difficult to focus on work processes in a contradictory environment. M. Puangshiri and H. Kleiner (2001), are discussing the retaliatory discrimination issues in their article "What Is Retaliatory Discrimination at Work?". They highlight the acute problems during working process, especially for workers with disabilities. Also, they discuss about the effects of retaliation and make conclusion that the retaliation always costs more than it is worth since damages in a retaliation claim are usually based on the wages that were lost (Puangshiri \& Kleiner, 2001).

The problems of workplace discrimination have been studied for so many years. Very interesting and useful article was published in Great Britain in 1998, which is about discrimination and the debates in England and Wales of that time (Roberts, Vickers, 1998). Z.V. Krinitcyna and E.V. Menshikova (Krinitcyna \& Menshikova, 2014) a discussed some relative issues in their article "Discrimination issues in the process of personnel selection". The paper discusses the concept of employment discrimination and its types, depending on the causes. The analysis of problems of social (gender and age) and psychological (racial and religious affiliation, disability) discrimination is given (Krinitcyna\&Menshikova, 2014). Linda R. Tropp (2006) in her 
article "Stigma and Intergroup Contact Among Members of Minority and Majority Status Groups" admits that beyond emphasizing conditions of the contact situation, we must also recognize that group members have histories of perceptions and experiences that are likely to inform their understanding of the intergroup relationship (Tropp, 2006). Stacey Sinclair and Jeff Huntsinger emphasize cultural aspects in their article "The Interpersonal Basis of Self-Stereotyping”. Their research found support for the affiliative social-tuning hypothesis, which argues that the stereotype-relevant evaluations of others will translate into self-evaluations and corresponding behavior when affiliative motivation is high as opposed to low (Sinclair \& Huntsinger, 2006).

Toni Schmader and Brian Lickel also discuss about ethnical and cultural characteristics. The data from the article "Stigma and Shame: Emotional Responses to the Stereotypic Actions of One's Ethnic Ingroup" provide evidence that shame plays a unique role in how individuals who are ethnically stigmatized react to the stereotypic behaviors of their ingroup. Although these actions elicit high levels of both shame and anger, it is shame that is predicted by the importance one places on his or her ethnic identity and it is shame that is distinctly predictive of distancing from the group or doing something to repair the image of the group in response (Schmader \& Lickel, 2006).

It is essential to study the discrimination pecularities in other types of firms, small and medium sized firms are really important in this regard for Georgia. Because the greatest number of firms occupies SMEs in our country (Abesadze \& Kakulia, 2008). There are some cases that employees agree to work in the environment that is not fair and free for them. The main reason is that they work for their living. So, the poverty makes people face such kind of problems and sometimes it is a normal for them (Kakhniashvili, 2017). So, first of all they need to be informed that there are some institutions in the country which can work for their rights and on the other hand releveant departments and Economic Policy Makers of the State should work for overcome the most accute problem, unemployment in the country and improve the socio-economic situation (Tugushi \& Paresashvili, 2007). For this reason, it is important to study the structure of unemployment in a systematic way (The Structure of Unemployment and Structural Unemployment in Georgia, 2016).

\section{METHODOLOGY}

The part of the questionnaire referring to discrimination issues included the questions like:

$>$ I have been a witness or victim of discrimination (discrimination includes direct or indirect arassment of a person aimed at or resulting in creating an intimidating, hostile, humiliating, degrading, or abusive environment for that person, or creating the circumstances for a person directly or indirectly causing their condition to deteriorate as compared to other persons in similar circumstances);

$>$ Organizational culture and policy of the company prevents discrimination;

$>$ The company adequately responds to discrimination;

$>$ Despite the differences there is no problem of communication between the employees. With the 
purpose of studying the issues of discrimination and statistical analyzing them statistically, some hypotheses were determined:

HP 1: Age, gender, education and respondent's position affects the part of the questionnaire referring to discrimination issues or the variables: Q1 - I have been a witness or victim of discrimination; Q2 Organizational culture and policy of the company prevents discrimination; Q3 - The company adequately responds to discrimination; Q4 - Despite the differences there is no problem of communication between the employees.

HP 2: Age affects the part of the questionnaire referring to discrimination issues

HP 3: Gender affects the part of the questionnaire referring to discrimination issues

HP 4: Education affects the part of the questionnaire referring to discrimination issues

HP 5: Respondent's position affects the part of the questionnaire referring to discrimination issues.

Evaluation of the impact of age, gender, education and respondent's positions on the part of the questionnaire referring to discrimination issues was performed using Multiple Analysis of Variance (MANOVA), which is done in SPSS by using multivariate analysis (factor analysis on several dependent variables). Using multivariate tests allowed us to receive the tables, based on which we made different conclusions. Correlation analysis was used to determine the strength of the connection between factors and dependent variables.

In addition to factor analysis, the paper also provides tables presenting the distribution of the frequency of discriminatory variables with their visual representation and consumer tables.

\section{DISCUSSION}

Frequency distribution tables of discriminatory variables and the corresponding figures show that $39 \%$ of the respondents have never been a witness or victim of discrimination; another $39 \%$ of the respondents consider that they have partly been a witness or victim of discrimination and $22 \%$ of the respondents (which is quite a large number) confirm to have been a witness or victim of discrimination (Table 1). It is noticable that in the compare with developed European countries Georgia has the lower percentage $-22 \%$, than for example, Germany, France, UK and not only Eurpean, besides them USA too accordying to the statista data based on the survey conducted in 2019 (McCarthy, 2019) (Fig. 1).

Table 1. I have been a witness or victim of discrimination

\begin{tabular}{|c|c|c|c|c|c|}
\hline \multicolumn{2}{|c|}{} & Frequency & Percent & Valid percent & $\begin{array}{c}\text { Cumulative } \\
\text { percent }\end{array}$ \\
\hline \multirow{3}{*}{ Valid } & Yes & 108 & $22 \%$ & $22 \%$ & $22 \%$ \\
\cline { 2 - 6 } & No & 191 & $\mathbf{3 9 \%}$ & $39 \%$ & $61 \%$ \\
\cline { 2 - 6 } & Partly & 189 & $\mathbf{3 9 \%}$ & $39 \%$ & $100 \%$ \\
\cline { 2 - 6 } & Total & $\mathbf{4 8 8}$ & $\mathbf{1 0 0 \%}$ & $\mathbf{1 0 0 \%}$ & \\
\hline
\end{tabular}

Source: Author's creation using SPSS 


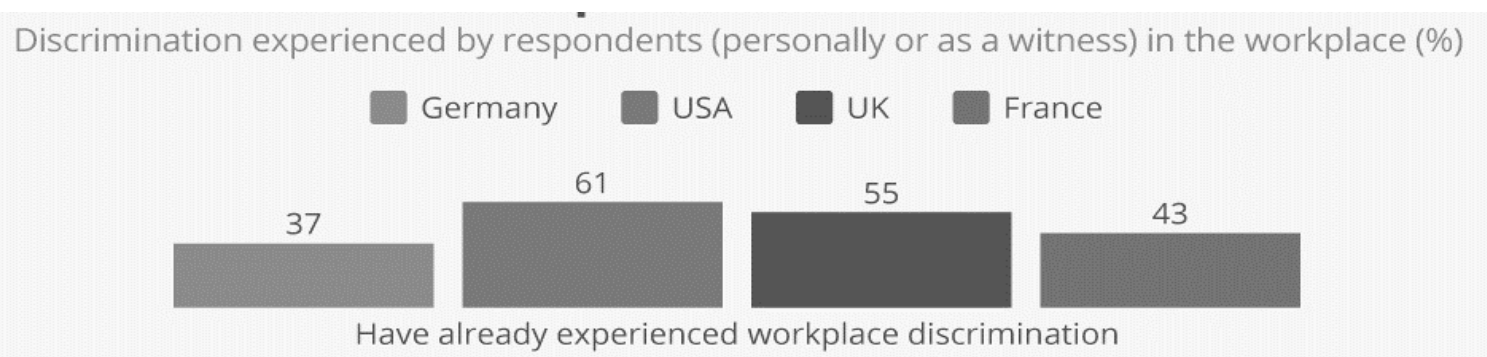

Most common trigger
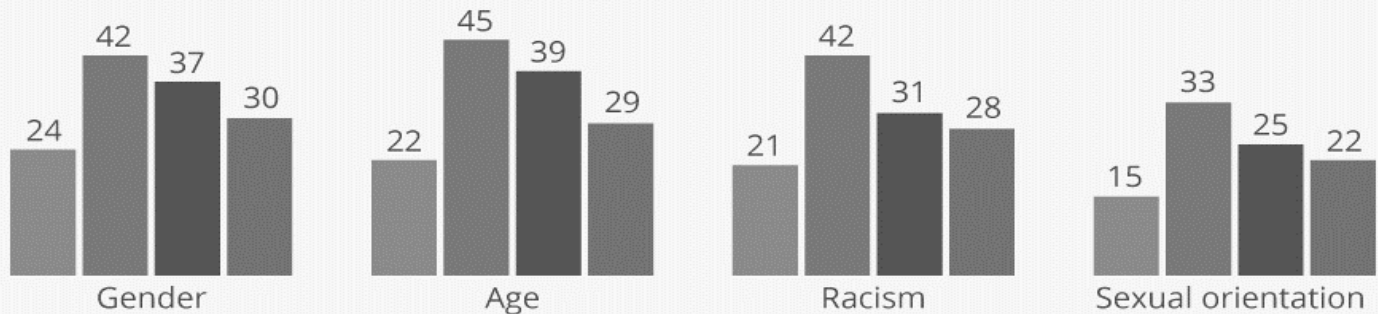

Fig. 1. Workplace Discrimination in Germany, USA, UK, France in 2019, (\%)

Source: Statista, https://www.statista.com/chart/19761/discrimination-experienced-by-respondents-in-the- workplacel

As an answer to the question "Organizational culture and policy of the company prevents discrimination", half of the respondents think that discrimination is prevented only partly; $33 \%$ consider that organizational culture and policy of the company prevents discrimination and $17 \%$ believe that discrimination is not prevented by organizational culture and policy (see Table 2).

Table 2. Organizational culture and policy of the company prevents discrimination

\begin{tabular}{|l|l|c|c|c|c|}
\hline \multicolumn{2}{|c|}{} & Frequency & Percent & $\begin{array}{c}\text { Valid } \\
\text { percent }\end{array}$ & $\begin{array}{c}\text { Cumulative } \\
\text { percent }\end{array}$ \\
\hline \multirow{4}{*}{ Valid } & Do not agree & 83 & $17 \%$ & $17 \%$ & $17 \%$ \\
\cline { 2 - 6 } & Partly agree & 246 & $\mathbf{5 0 \%}$ & $50 \%$ & $67 \%$ \\
\cline { 2 - 6 } & Fully agree & 159 & $33 \%$ & $33 \%$ & $100 \%$ \\
\cline { 2 - 6 } & Total & $\mathbf{4 8 8}$ & $\mathbf{1 0 0 \%}$ & $\mathbf{1 0 0 \%}$ & \\
\hline
\end{tabular}

Source: Author's creation using SPSS

It is really worthy of attention that quite a large number of respondents (17\%) consider that organizational culture and policy of the company does not prevent discrimination.

$36 \%$ of the respondents think that companies only partly respond to discrimination (Table 3 ), $32 \%$ consider that the cases of discrimination are responded by companies and sadly, another $32 \%$ think that companies do not respond to discrimination. 
Table 3. The company adequately responds to discrimination

\begin{tabular}{|c|c|c|c|c|c|}
\hline \multicolumn{2}{|c|}{} & Frequency & Percent & $\begin{array}{c}\text { Valid } \\
\text { percent }\end{array}$ & $\begin{array}{c}\text { Cumulative } \\
\text { percent }\end{array}$ \\
\hline \multirow{3}{*}{ Valid } & Yes & 156 & $32 \%$ & $32 \%$ & $32 \%$ \\
\cline { 2 - 6 } & No & 154 & $32 \%$ & $32 \%$ & $64 \%$ \\
\cline { 2 - 6 } & Partly & 178 & $36 \%$ & $36 \%$ & $100 \%$ \\
\cline { 2 - 6 } & Total & $\mathbf{4 8 8}$ & $\mathbf{1 0 0 \%}$ & $\mathbf{1 0 0 \%}$ & \\
\hline \multicolumn{7}{|c|}{ Source: Author's creation using SPSS } \\
\hline
\end{tabular}

$39 \%$ of the respondents believe that despite the differences there is no problem of communication between the employees, $35 \%$ partly agree that there is no problem of communication and quite a large number of respondents $(26 \%)$ do not agree that despite the differences there is no problem of communication between the employees.

Table 4. Despite the differences there is no problem of communication between the employees

\begin{tabular}{|c|c|c|c|c|c|}
\hline \multicolumn{2}{|c|}{} & Frequency & Percent & $\begin{array}{c}\text { Valid } \\
\text { percent }\end{array}$ & $\begin{array}{c}\text { Cumulative } \\
\text { percent }\end{array}$ \\
\hline \multirow{3}{*}{ Valid } & Yes & 190 & $\mathbf{3 9 \%}$ & $39 \%$ & $39 \%$ \\
\cline { 2 - 6 } & No & 128 & $26 \%$ & $26 \%$ & $65 \%$ \\
\cline { 2 - 6 } & Partly & 170 & $35 \%$ & $35 \%$ & $100 \%$ \\
\cline { 2 - 6 } & Total & $\mathbf{4 8 8}$ & $\mathbf{1 0 0 \%}$ & $\mathbf{1 0 0 \%}$ & \\
\hline \multicolumn{7}{|c}{ Source: Author's creation using SPSS } \\
\hline
\end{tabular}

Visual representation of the distribution of the frequency of discriminatory variables is presented below.

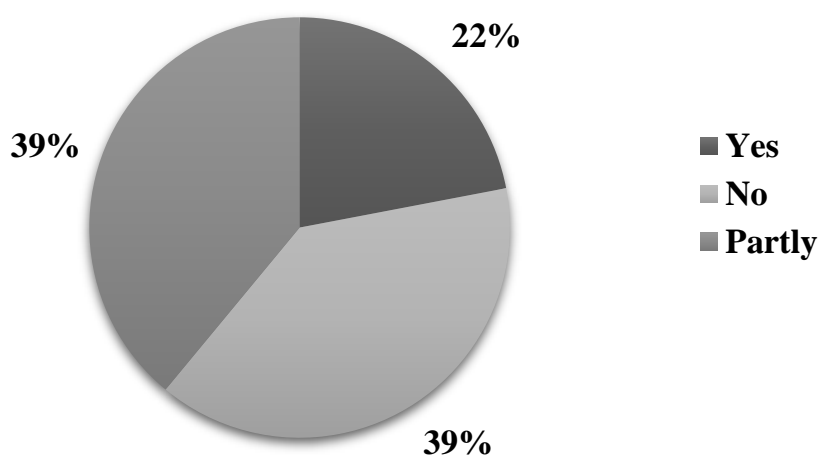

Fig. 2. Distribution of the answers of "I have been a witness or victim of discrimination" Source: Author's creation using SPSS 
According to the given Figures above, it should be noted that the descrimination problem is really one of the acutest ones at the workplaces in Georgia. To our mind the most problematic part of workforce are who do not speak out loud about their problems or they partly show their attitude toward the discrimination. If we observe the data well, we notice that the most percentage comes to exactly such kind of respodents. It means that they are potentially more "yes" than "no" discriminated employees.

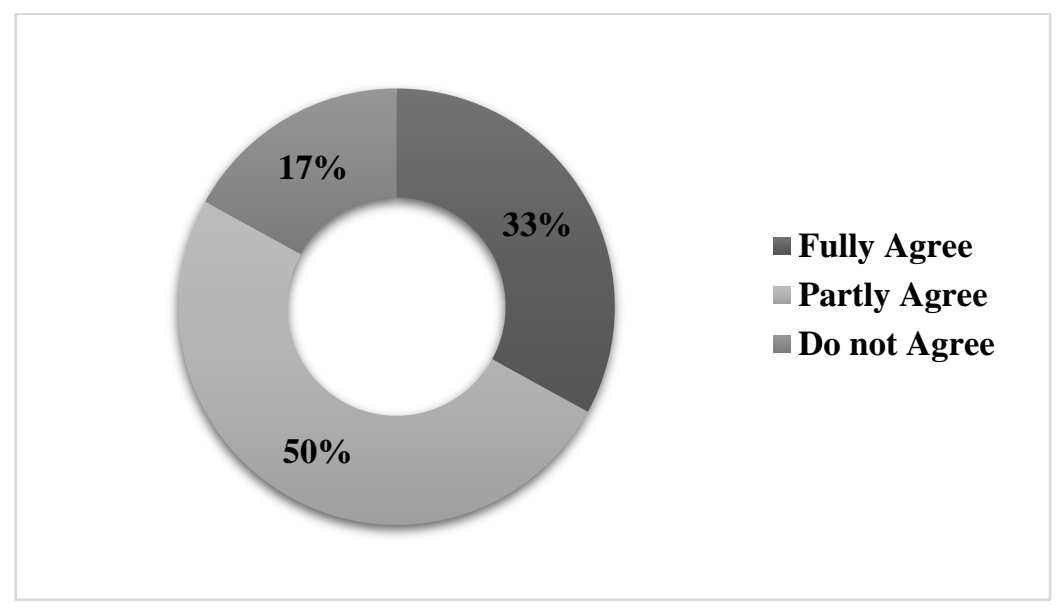

Fig. 3. Distribution of the answers of "Organizational culture and policy of the company prevents discrimination" Source: Author's creation using SPSS

The second problem is that in the case when people speak about their problems and report them. What is the answer of the company, government or other institutions? In most cases in Georgia after reporting the workplace problems, they get the aid partly or not at all. Although, surpirsingly or not Georgia is not the only country where these problems exist. The surA a sweeping study of 193 countries by the UCLA World Policy Analysis (University of California, Los Angeles) reveals critical gaps in legal protections against discrimination on the job. The researchers found that $28 \%$ of high-income countries do not have any protections, compared to $19 \%$ of low-income countries and $23 \%$ of middle-income countries. Even in countries that prohibit discrimination, substantial gaps in legal protections exist. Globally, 51\% of countries offer no protection from retaliation against workers who report discriminatory treatment based on race or ethnicity, preventing individuals from accessing justice, the study revealed (UCLA World Policy Analysis Survey, 2020).

So, as graphic analysis of frequency distribution shows, great attention should be paid to the issues of discrimination and looking for the ways to eliminate such incidents. Distribution of frequency of the company's response to discrimination in accordance with the respondents' position and education is presented on Table 5

As Table 5 shows, the majority of the respondents answering the question about the company's respond to discrimination are on non-managerial positions. Despite education, 169 of the respondents think that cases of 
discrimination are only partly responded, 146 respondents consider that the company does not respond to discrimination and only 106 respondents consider that discrimination is responded.

Most of the respondents with secondary education think that the company does not respond to discrimination incidents at all.

Table 5. Respodent's position

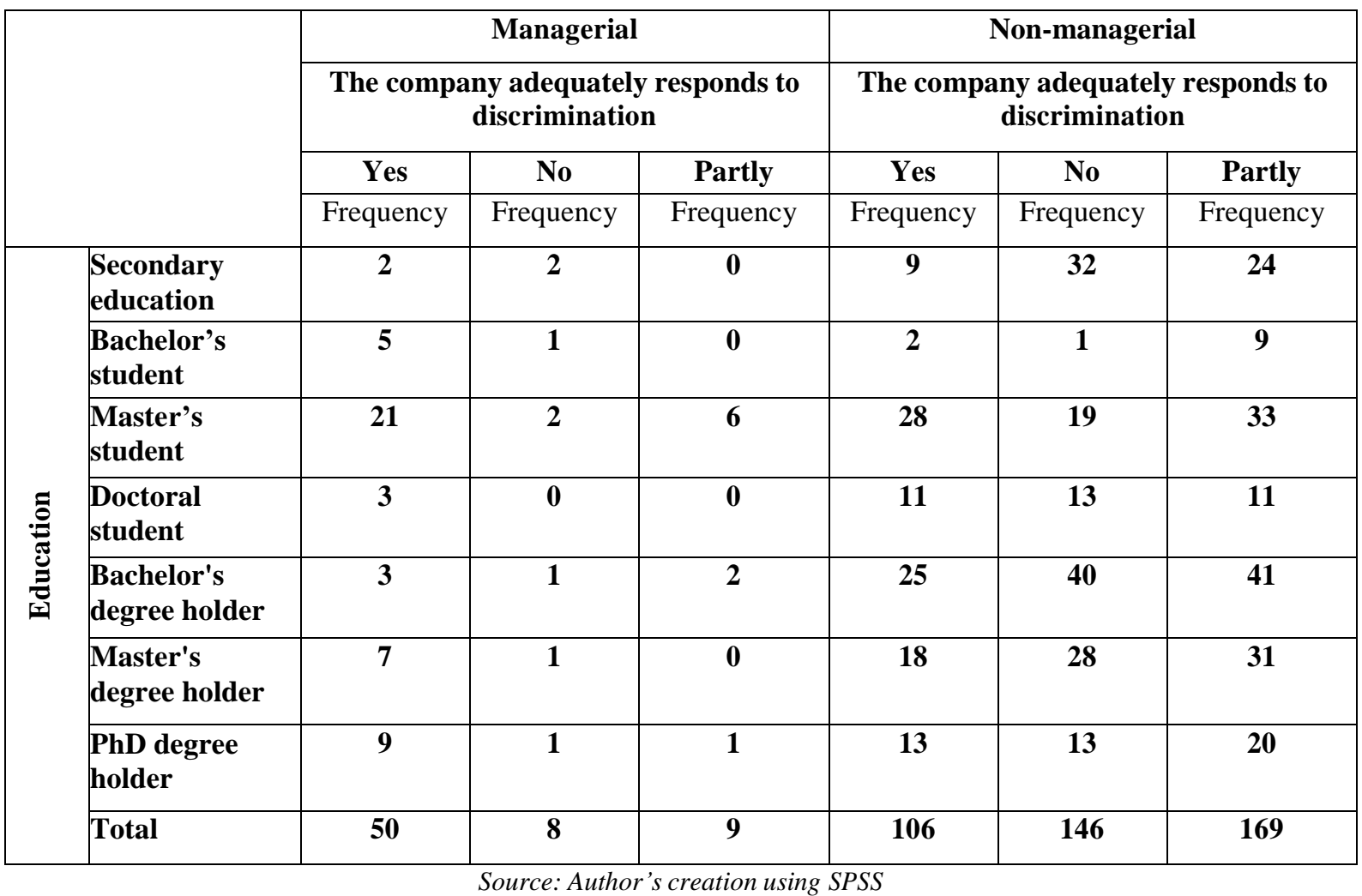

Majority of master's students with active status, as well as master's degree holders and most of the $\mathrm{PhD}$ degree holders consider that discrimination is partly responded.

Bachelor's degree holders working on non-managerial positions are most active - 41 of them think that discrimination is only partly responded by the organization and 40 of them think that discrimination is not responded, which clearly indicates the necessity of solving the issues of discrimination.

Master's degree holders, working both on managerial and non-managerial (21 master's degree holders on managerial and 28 master's degree holders on non-managerial) positions, are most active in the category "Yes".

The consumer table below (Table 6) illustrates frequency distribution of the variable "Organizational culture and policy of the company prevents discrimination" by gender and age. 
Table 6. Organizational culture and policy of the company prevents discrimination

\begin{tabular}{|c|c|c|c|c|c|c|c|}
\hline & $\begin{array}{l}\text { Do not } \\
\text { agree }\end{array}$ & Partly agree & Fully agree & Total \\
\hline & & & & Frequency & Frequency & Frequency & Frequency \\
\hline \multirow[t]{8}{*}{ q2 gender } & \multirow{4}{*}{ Female } & \multirow{4}{*}{ Age } & $18-32$ & 6 & 22 & 23 & 51 \\
\hline & & & $33-42$ & 9 & 22 & 18 & 49 \\
\hline & & & $43-52$ & 13 & 28 & 16 & 57 \\
\hline & & & 52> & 9 & 26 & 13 & 48 \\
\hline & \multirow[t]{4}{*}{ Male } & \multirow[t]{4}{*}{ Age } & $18-32$ & 11 & 27 & 15 & 53 \\
\hline & & & $33-42$ & 13 & 34 & 28 & 75 \\
\hline & & & $43-52$ & 15 & 58 & 25 & 98 \\
\hline & & & $52>$ & 7 & 29 & 21 & 57 \\
\hline
\end{tabular}

Source: Author's creation using SPSS

As table 6 shows, only female respondents aged between 18 and 32 years old consider that organizational culture and policy of the company prevents discrimination.

Respondents of both genders belonging to other age groups consider that organizational culture and policy of the company only partly prevents discrimination.

Analysis of graphical and consumer tables show that different approach and measures are needed for the organization.

Multiple analysis of variance (MANOVA) was used to examine and prove the hypotheses. We constructed tables by using its tests, based on which we made some conclusions and examined hypotheses.

Table 7, received as a result of dispersion analysis, shows the outcome of Levene's Test of equality of error variances. Table 7 shows which of the particular discriminative variables are affected by the factors like age, gender, education and respondent's positions.

According to Levene's test, the combination of these factors affects all four dependent variables. According to Table 7, there is a statistically important connection between the given factors and each of the variables. Statistically significant connection is found with Q1, Q3 and Q4 on the level of $0.01(\mathrm{P}<0.01)$, and with Q2 on the level of $0.05(\mathrm{P}=0.047)$. However, according to the $\mathrm{F}$ test, variable $\mathrm{Q} 3$ (The company adequately responds to discrimination) is most affected by the factors ( $\mathrm{F}=2,175, \mathrm{P}$ does not exceed 0.001$)$; it is followed by variable Q1 (I have been a witness or victim of discrimination) ( $F=2,074$, P does not exceed 0.001- $b$ ), then variable Q4 (Despite the differences there is no problem of communication between the employees) $(\mathrm{F}=2,030$, $\mathrm{P}$ does not exceed 0.001) and variable Q2 (Organizational culture and policy of the company prevents discrimination $)$ is least affected $(\mathrm{F}=1.298, \mathrm{P}=0.048)$.

Table 7 proved Hypothesis 1 - the combination of the factors like age, gender, education and respondent's position affects the part of the questionnaire referring to discrimination issues: Q1 - I have been a witness or victim of discrimination; Q2 - Organizational culture and policy of the company prevents discrimination; Q3 
- The company adequately responds to discrimination; Q4 - Despite the differences there is no problem of communication between the employees.

Table 7. Levene's Test of Equality of Error Variances

\begin{tabular}{|c|c|c|c|c|}
\hline \multicolumn{5}{|c|}{} \\
\hline $\begin{array}{c}\text { Q1 I have been a witness or victim of discrimination } \\
\text { Q2 Organizational culture and policy of the company } \\
\text { prevents discrimination }\end{array}$ & 2.074 & 93 & 394 & .000 \\
\hline Q3 The company adequately responds to discrimination & 2.175 & 93 & 394 & .000 \\
\hline $\begin{array}{r}\text { Q4 Despite the differences there is no problem of } \\
\text { communication between the employees }\end{array}$ & 2.030 & 93 & 394 & .000 \\
\hline
\end{tabular}

Source: Author's creation using SPSS

\section{Assessment}

Assessing the impact of individual factors on the part of the questionnaire referring to discrimination issues:

\section{Assessing the impact of age}

Table 8, received as a result of dispersion analysis, shows the assessment of the impact of age variable on the part of the questionnaire referring to discrimination issues.

As shown in Table 8, age affects only variable Q3 (the company's response to discrimination) as level of statistical significance is equal to 0.49 (which is less than 0.05 ), which means that different groups of age have different opinions regarding this question (Q3).

The correlation analysis (Table 12) between age and Q3 variable (the company's response to discrimination) revealed weak positive correlation (correlation coefficient $\mathrm{r}=0.102$ ).

Therefore, HP2 was proved only partially - age affects Q3 variable (weak positive correlation of the company's respond to discrimination) and does not affect the following variables: Q1 - I have been a witness or victim of discrimination; Q2 - Organizational culture and policy of the company prevents discrimination; Q4 - Despite the differences there is no problem of communication between the employees. Thus, the opinions of various age groups regarding the company's respond to discrimination are quite different.

Table 8. Univariate Tests

\begin{tabular}{|l|l|c|c|c|c|c|c|}
\hline \multicolumn{2}{|c|}{ Dependent Variable } & $\begin{array}{c}\text { Sum of } \\
\text { Squares }\end{array}$ & df & $\begin{array}{c}\text { Mean } \\
\text { Square }\end{array}$ & F & Sig. & $\begin{array}{c}\text { Partial } \\
\text { Eta } \\
\text { Squared }\end{array}$ \\
\hline $\begin{array}{l}\text { Q1 I have been a witness or } \\
\text { victim of discrimination }\end{array}$ & Contrast & 1,779 & 3 & 0,593 & 1,071 & 0,361 & 0,008 \\
\cline { 2 - 9 } & Error & 218,237 & 394 & 0,554 & & & \\
\hline Q 2 Organizational culture and & Contrast & 2,284 & 3 & 0,761 & 1,669 & 0,173 & 0,013 \\
\hline
\end{tabular}




\begin{tabular}{|l|l|c|c|c|c|c|c|}
\hline $\begin{array}{l}\text { policy of the company prevents } \\
\text { discrimination }\end{array}$ & Error & 179,677 & 394 & 0,456 & & & \\
\hline $\begin{array}{l}\text { Q3 The company adequately } \\
\text { responds to discrimination }\end{array}$ & Contrast & 5,049 & 3 & 1,683 & 2,502 & 0,049 & 0,019 \\
\cline { 2 - 8 } & Error & 264,967 & 394 & 0,673 & & & \\
\hline $\begin{array}{l}\text { Q4 Despite the differences } \\
\text { there is no problem of } \\
\text { communication between the } \\
\text { employees }\end{array}$ & Contrast & 3,392 & 3 & 1,131 & 1,557 & 0,199 & 0,012 \\
\cline { 2 - 8 } & Error & 286,091 & 394 & 0,726 & & & \\
\hline
\end{tabular}

Source: Author's creation using SPSS

\section{Assessing the impact of gender on the part of the questionnaire referring to discrimination issues}

Assessment of the impact of gender is provided based on Table 9 received as a result of dispersion analysis

Table 9. Univariate Tests

\begin{tabular}{|l|l|c|c|c|c|c|c|}
\hline \multicolumn{2}{|l|}{} & $\begin{array}{c}\text { Sum of } \\
\text { Square s }\end{array}$ & df & $\begin{array}{c}\text { Mean } \\
\text { Square }\end{array}$ & F & Sig. & $\begin{array}{c}\text { Partial } \\
\text { Eta Squared }\end{array}$ \\
\hline $\begin{array}{l}\text { Q1 I have been a witness or } \\
\text { victim of discrimination }\end{array}$ & Contrast & 0,433 & 1 & 0,433 & 0,765 & 0,382 & 0,002 \\
\cline { 2 - 8 } & Error & 228,756 & 404 & 0,566 & & & \\
\hline $\begin{array}{l}\text { Q 2 Organizational culture and } \\
\text { policy of the company prevents } \\
\text { discrimination }\end{array}$ & Contrast & 0,483 & 1 & 0,483 & 1,069 & 0,302 & 0,003 \\
\cline { 2 - 8 } & Error & 182,330 & 404 & 0,451 & & & 0,044 \\
\hline $\begin{array}{l}\text { Q3 The company adequately } \\
\text { responds to discrimination }\end{array}$ & Contrast & 2,591 & 1 & 2,591 & 4,099 & 0,010 \\
\hline & Error & 264.967 & 394 & 0.673 & & & \\
\hline $\begin{array}{l}\text { Q4 Despite the differences there is } \\
\text { no problem of communication } \\
\text { between the employees }\end{array}$ & Contrast & 0,000 & 1 & 0,000 & 0,000 & 0,000 & 0,000 \\
\cline { 2 - 8 } & Error & 286.091 & 394 & 0.726 & & & \\
\hline
\end{tabular}

Source: Author's creation using SPSS

As shown in Table 9, which was received as a result of dispersion analysis, gender also affects only variable Q3 (the company's response to discrimination), statistically significant correlation on the level of 0.05 is shown between gender and the above variable (the level of statistical significance is equal to 0.44 , which is less than 0.05). Therefore, the opinions of female and male respondents regarding this issue are different.

The correlation analysis (Table 12) between gender and Q3 variable (the company's response to discrimination) showed very weak positive correlation (correlation coefficient $r=0.077$ ).

Therefore, HP3 was proved partially - gender affects only Q3 variable (the company responds to discrimination) with very weak positive correlation and does not affect the following variables: Q1 - I have been a witness or victim of discrimination; Q2 - Organizational culture and policy of the company prevents discrimination; Q4 - Despite the differences there is no problem of communication between the employees.

\section{Assessing the impact of education on the part of the questionnaire referring to discrimination issues}


Assessment of the impact of education on the part of the questionnaire referring to discrimination issues is provided based on Table 10 received as a result of dispersion analysis.

Table 10. Univariate Tests

\begin{tabular}{|l|l|c|c|c|c|c|c|}
\hline Dependent Variable & $\begin{array}{c}\text { Sum of } \\
\text { Squares }\end{array}$ & df & Mean Square & F & Sig. & $\begin{array}{c}\text { Partial Eta } \\
\text { Squared }\end{array}$ \\
\hline $\begin{array}{l}\text { Q1 I have been a } \\
\text { witness or victim of } \\
\text { discrimination }\end{array}$ & Contrast & 4,337 & 6 & 0,723 & 1,305 & 0,254 & 0,019 \\
\cline { 2 - 8 } & Error & 218,237 & 394 & 0,554 & & & \\
\hline $\begin{array}{l}\text { Q 2 Organizational } \\
\text { culture and policy of the } \\
\text { company prevents } \\
\text { discrimination }\end{array}$ & Contrast & 2,261 & 6 & 0,377 & 0,826 & 0,550 & 0,012 \\
\cline { 2 - 8 } & Error & 179,677 & 394 &, 456 & & & \\
\hline $\begin{array}{l}\text { Qdequately responds to } \\
\text { discrimination }\end{array}$ & Contrast & 7,380 & 6 & 1,230 & 1,829 & 0,092 & 0,027 \\
\cline { 2 - 8 } & Error & 264,967 & 394 & 0,673 & & & 0,023 \\
\hline $\begin{array}{l}\text { Q4 Despite the } \\
\text { differences there is no } \\
\text { problem of } \\
\text { communication between } \\
\text { the employees }\end{array}$ & Contrast & 6,678 & 6 & 1,113 & 1,533 & 0,166 & 0 \\
\cline { 2 - 8 } & Error & 286,091 & 394 & 0,726 & & & \\
\hline
\end{tabular}

Source: Author's creation using SPSS

As shown in Table 10, the education variable does not affect any dependent variable; the level of statistical significance for each variable exceeds 0.05 .

Accordingly, HP4 was not proved - education does not affect the part of the questionnaire referring to discrimination issues.

\section{Assessing the impact of the respondent's position on the part of the questionnaire referring to} discrimination issues

Assessment of the impact of the respondent's position is provided based on Table 11 received as a result of dispersion analysis.

Table 11. Univariate Tests

\begin{tabular}{|l|l|c|c|c|c|c|c|}
\hline Dependent Variable & $\begin{array}{c}\text { Sum of } \\
\text { Squares }\end{array}$ & df & $\begin{array}{c}\text { Mean } \\
\text { Square }\end{array}$ & F & $\begin{array}{c}\text { Sig. } \\
\text { Partial Eta } \\
\text { Squared }\end{array}$ \\
\hline $\begin{array}{l}\text { Q1 I have been a witness } \\
\text { or victim of discrimination }\end{array}$ & Contrast & 1,255 & 1 & 1,255 & 2,217 & 0,026 & 0,005 \\
\cline { 2 - 9 } & Error & 228,756 & 404 & 0,566 & & & \\
\hline $\begin{array}{l}\text { Q 2 Organizational culture } \\
\text { and policy of the company } \\
\text { prevents discrimination }\end{array}$ & Contrast & 0,010 & 1 & 0,010 & 0,021 & 0,884 & 0,000 \\
\cline { 2 - 9 } & Error & 182,330 & 404 & 0,451 & & & 0,102 \\
\hline
\end{tabular}




\begin{tabular}{|l|l|c|c|c|c|c|c|}
\hline $\begin{array}{l}\text { adequately responds to } \\
\text { discrimination }\end{array}$ & Error & 255,390 & 404 & 0,632 & & & \\
\hline $\begin{array}{l}\text { Q4 Despite the differences } \\
\text { there is no problem of } \\
\text { communication between } \\
\text { the employees }\end{array}$ & Eontrast & 6,774 & 1 & 6,774 & 9,356 & 0,002 & 0,023 \\
\cline { 2 - 8 } & Error & 292,523 & 404 & 0,724 & & & \\
\hline
\end{tabular}

Table 11 shows that the respondent's position affects Q1, Q3 and Q4 variables - with statistically significant correlation on the level of 0.01 with Q3 and Q4 and on the level of 0.05 with Q1. According to F tests and the level of statistical significance, variable Q3 (the company responds to discrimination) is most affected $(\mathrm{F}=28,967)$, it is followed by variable $\mathrm{Q} 4$ (Despite the differences there is no problem of communication between the employees), where $\mathrm{F}=6,774$, and $\mathrm{P}<0.01$ and finally, variable $\mathrm{Q} 1$ (I have been a witness or victim of discrimination) with statistical significance on the level $0.05(\mathrm{P}=0.026)$.

Consequently, the opinions of the respondents working on managerial and non-managerial positions turned out to be quite various about Q1, Q3 and Q4 variables.

The correlation analysis (Table 12) between the respondent's position and Q3 variable (the company's response to discrimination) revealed positive correlation of medium strength (correlation coefficient $r=0.317$ ); weak positive correlation was shown between the respondent's position and the variables Q4 (despite the differences there is no problem of communication between the employees) and Q1 (I have been a witness or victim of discrimination).

Accordingly, HP4 was partly proved - the respondent's position affects variable Q3 (The company responds to discrimination) with positive correlation of medium strength and on the variables Q4 (despite the differences there is no problem of communication between the employees) and Q1 (I have been a witness or victim of discrimination) with weak positive correlation and does not affect variable Q2 (Organizational culture and policy of the company prevents discrimination).

Table12. Correlations

\begin{tabular}{|l|l|c|c|c|c|}
\hline \multicolumn{2}{|l|}{} & Age & Gender & Education & $\begin{array}{c}\text { Respondent's } \\
\text { position }\end{array}$ \\
\hline $\begin{array}{l}\text { I have been a witness or victim } \\
\text { of discrimination }\end{array}$ & $\begin{array}{l}\text { Pearson } \\
\text { Correlation }\end{array}$ & 0,027 & $-0,027$ & $-0,027$ & $0.102^{*}$ \\
\cline { 2 - 6 } & Sig. (2-tailed) & 0,547 & 0,551 & 0,557 & $\mathbf{0 , 0 2 4}$ \\
\cline { 2 - 6 } & $\mathbf{N}$ & 488 & 488 & 488 & 488 \\
\hline $\begin{array}{l}\text { Organizational culture and } \\
\text { policy of the company prevents }\end{array}$ & $\begin{array}{l}\text { Pearson } \\
\text { Correlation }\end{array}$ & $-0,036$ & $-0,006$ & $-0,001$ & $-0,014$ \\
\hline
\end{tabular}




\begin{tabular}{|c|c|c|c|c|c|}
\hline \multirow[t]{2}{*}{ discrimination } & Sig. (2-tailed) & 0,429 & 0,886 & 0,980 & 0,765 \\
\hline & $\mathrm{N}$ & 488 & 488 & 488 & 488 \\
\hline \multirow[t]{3}{*}{$\begin{array}{l}\text { The company adequately } \\
\text { responds to discrimination }\end{array}$} & $\begin{array}{l}\text { Pearson } \\
\text { Correlation }\end{array}$ & $0.102^{*}$ & 0,077 & $-0,018$ & $0.317^{* *}$ \\
\hline & Sig. (2-tailed) & 0,024 & 0,048 & 0,695 & $\mathbf{0 , 0 0 0}$ \\
\hline & $\mathrm{N}$ & 488 & 488 & 488 & 488 \\
\hline \multirow[t]{3}{*}{$\begin{array}{l}\text { Despite the differences there is } \\
\text { no problem of communication } \\
\text { between the employees }\end{array}$} & $\begin{array}{l}\text { Pearson } \\
\text { Correlation }\end{array}$ & 0,074 & 0,061 & $-0,035$ & $0.134^{* *}$ \\
\hline & Sig. (2-tailed) & 0,101 & 0,179 & 0,438 & $\mathbf{0 , 0 0 3}$ \\
\hline & $\bar{N}$ & 488 & 488 & 488 & 488 \\
\hline
\end{tabular}

Source: Author's creation using SPSS

As statistical analysis shows, we have received many negative answers regarding the issues of discrimination and this should be taken into consideration while decision-making and leading the management of the organization efficiently.

\section{CONCLUSIONS}

For millions of people in the world as well as in Georgia workplace discrimination is a real problem they concern. So, State institutes, facilitator organizations and the society should realize these problems and try together to deal with them.

As statistical analysis provided in this article shows, we have received many negative answers regarding the issues of discrimination in Georgia and this should be taken into consideration while decision-making and leading the management of the organization efficiently. And what is more important, as the authors we consume that there is always even a little be worse situation in real than such kind of research show, because no research can reflect the situation for 100 percent. Raising the quality of job opportunities available to all the workers that allow for a better work-life balance would improve their well- being, enhance their incentives to participate in the labour market and reduce the underutilization of their skills.

\section{Conflict of interests}

The authors declare no conflict of interest.

\section{References}

4 Examples of Workplace Discrimination. (2017). MDC Legal, Types Of Discrimination. https://mdclegal.com.au/4-examples-workplace-discrimination/

Abesadze R., Kakulia V. (2008). Macroeconomic Regulation Mechanism Of Small Business In Georgia, Monograph, Tbilisi 
Discrimination And Harrassment In The Workplace (2019). NCSL, Bloomberg Law, https://www.ncsl.org/research/labor-and-employment/discrimination.aspx

Discrimination By Type. EEOC. Accessed June 22, 2020, https://www.eeoc.gov/discrimination-type

Roberts, P., Vickers, L. (1998). Harassment At Work As Discrimination: The Current Debate In England And Wales. International Journal of Discrimination and the Law, Vol. 3, Pp . 91-114 1358-2291/98, A B Academic Publishers. Printed In Great Britain, https://journals.sagepub.com/doi/pdf/10.1177/135822919800300202

Kakhniashvili N. (2017). Financial Aspects of Poverty Reduction In Georgia, Summary of the Doctoral Thesis, P. 29

Krinitcyna Z.V., Menshikova E.V. (2014). DiscriminationiIssues in the Process of personnel selection. Procedia - Social And Behavioral Sciences 166 (2015), pp.12 -17. https://doi.org/10.1016/j.sbspro.2014.12.475

Kharadze, N., Paichadze, N., \& Paresashvili, N. (2019). General Trends of Business Career Management. European Journal Of Economics And Business Studies, 5(1), 153-177. doi:10.26417/ejes.v5i1.p153-177

McCarthy, N. (2019). How Common Is Workplace Discrimination? Statista. https://www.statista.com/chart/19761/discrimination-experienced-by-respondents-in-the-workplace/

Paresashvili, N., Abesadze, N., Kinkladze, R., Chitaladze, N., \& Edzgveradze, T. (2021). Georgian Labour Market during the Coronavirus Pandemic. SHS Web of: Globalization and its Socio-Economic Consequences 2020 (Vol. 92). DOI:10.1051/shsconf/20219207046, EDP Sciences.

Paresashvili, N., Nikvashvili, M. (2019). Career Management Peculiarities in Educational Institutions. South East European Journal of Economics and Business, 5 (1), 207-224. DOI: http://dx.doi.org/10.26417/ejes.v5i1.p207-224

Paresashvili, N., Gurbanov, N., Gechbaia, B., Goletiani, K., Edzgveradze, T. (2020). Significant Issues Of Organizational Conflict Management. 55th International Scientific Conference on Economic and Social Development, dedicated to the 90th anniversary of the Azerbaijan State University of Economics (UNEC), Baku, pp. 457-464.

Paresashvili, N., Okruashvili, N., Chitaladze, K. (2021). The Need for Cross-Cultural Competencies In A Multicultural Environment. 15th International Technology, Education and Development Conference INTED2021, pp. $9946-9952$. ISBN: 978-84-09-27666-0, ISSN: 2340-1079, doi: 10.21125/inted.2021.2072

Paresashvili, N., Okruashvili, N., Edzgveradze, T. (2020). Global Challenges in the Human Capital Formation Process (The Case of Georgia). In Monograph: Management: Strategic Imperatives and Trends of Transformations. pp. 128138. Kiev.

Prohibited Employment Policies/Practices. EEOC. Accessed June 22, 2020, https://www.eeoc.gov/prohibitedemployment-policiespractices

Puangshiri M., Kleiner B.H. (2001). What is retaliatory discrimination at work? Equal Opportunities International. Volume 20 Number 5/6/7, pp. 37-40, ISSN: 0261-0159, https://doi.org/10.1108/02610150110787001

Schmader T., Lickel B. (2006). Stigma and Shame: Emotional Responses to the Stereotypic Actions of One's Ethnic Ingroup, Chapter 13, pp. 261-286, eBook ISBN 9781410617057

Sims, C. S., Dalal, R. S. (2008). Defining generalized workplace discrimination. Poster presented at the annual meeting of the Society for Industrial and Organizational Psychology (San Francisco, CA, USA).

Sinclair S., Huntsinger J. (2006). The Interpersonal Basis of Self-Stereotyping, Stigma and Group Inequality, London, Chapter 12, pp. 235-260. eBook ISBN 9781410617057

The Structure of Unemployment and Structural Unemployment in Georgia (2016). Georgian Foundation for Strategic and International Studies, GFSIS, https://www.gfsis.org/publications/view/2456

Tropp L.R. (2006). Stigma and Intergroup Contact Among Members of Minority and Majority Status Groups. Stigma and Group Inequality, London, Chapter 9, eBook ISBN9781410617057, pp. 171-192

TugushiM.,Paresashvili N. (2007). Unemployment and its social-economic outcomes in Georgia, Journal The Economics, Number 3-4. 60-65

UCLA World Policy Analysis Survey. (2020). Https://Newsroom.Ucla.Edu/Releases/Gaps-InWorkplace- Protections 


\section{About the authors}

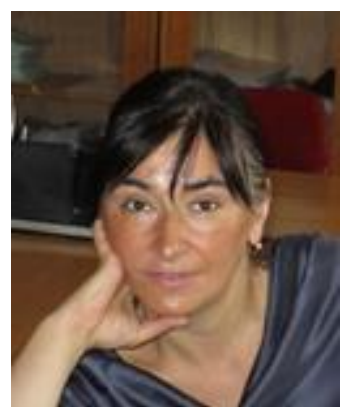

\section{Nino PARESASHVILI}

Doctor of Economics, Associate Professor

Economics and Business Faculty, Ivane Javakhishvili Tbilisi State University, Georgia

Research interests: Management, Organizational Management, Organizational Behavior, Conflict Management, Cross-cultural Management.

She has taken part in different scientific and educational conferences.

ORCID ID: https://orcid.org/0000-0001-6738-5409

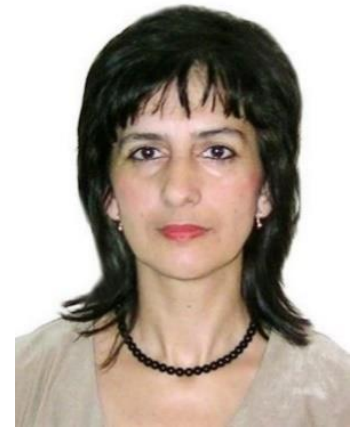

\section{Mzia TIKISHVILI}

Doctor of Economics, Associate Professor

Economics and Business Faculty, Ivane Javakhishvili Tbilisi State University, Georgia Research interests: Informatics, Information Management in Economics and Business

ORCID ID: https://orcid.org /0000-0002-5240-9030

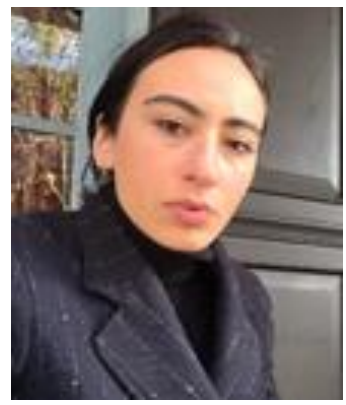

\section{Teona EDZGVERADZE}

Student at Faculty Of Economics And Business, Ivane Javakhishvili Tbilisi State University, Georgia

She has taken part in different scientific and educational conferences.

ORCID ID: https://orcid.org/0000-0002-8517-5285

Copyright @ 2020 by author(s) and ACCESS Publishing Press This work is licensed under the Creative Commons Attribution International License (CC BY) 